\title{
Awareness on Diagnosis of Fluorosis Stains Among Dental Students
}

\author{
Chaitanya Shree P1', Dhanraj Ganapathy², Subhashree $\mathrm{R}^{3}$ and Rakshagan V4 \\ ${ }^{1}$ Saveetha Dental College Saveetha Institute of Medical and Technical \\ Sciences (SIMATS) Saveetha University Chennai - 600 077, India \\ ${ }^{2}$ Professor and Head of the department Department of Prosthodontics Saveetha Dental College Saveetha \\ Institute of Medical and Technical Sciences (SIMATS) Saveetha University Chennai - 600077 \\ ${ }^{3}$ Senior Lecturer Department of Prosthodontics Saveetha Dental College and Hospitals Saveetha \\ Institute of Medical and Technical Sciences Saveetha University Chennai -77, India \\ ${ }^{4}$ Senior Lecturer Department of Prosthodontics Saveetha Dental College and Hospitals Saveetha \\ Institute of Medical and Technical Sciences Saveetha University Chennai -77, India
}

\section{ABSTRACT}

Dental fluorosis occurs due to ingestion of excess fluoride during tooth formation stage. Fluoride decreases the incidence of dental caries but when exceeded above normal limit, it causes fluorosis. Fluorosis stains appear as white opaque stains. If the dental fluorosis is more severe, it appears brown due to secondary staining. The aim of the present study is to analyse the awareness levels on diagnosis of fluorosis stains among dental students. The present study is a survey based study. A set of 12 questionnaires were prepared and distributed among students of Saveetha Dental College. The questionnaires are about fluorosis, its diagnosis and treatment. We found that only a smaller number of people are not aware of fluorosis stains and majority of them say that the cause is consumption of drinks. Majority of the students are aware of the diagnosis and treatment plan for fluorosis stains. Hence the present study showed that there is proper awareness on fluorosis stains among dental students. Though there is proper awareness of fluorosis stains, there are few populations who are not aware of its diagnosis. Hence proper awareness on fluorosis should be created among students and other populations.

KEY WORDS: FLUOROSIS, SA/GAG TEST, STAINS, WHITE.

\section{INTRODUCTION}

Fluorosis occurs as a result of excess fluoride ingestion. It appears initially as white opaque surface and leads to brownish discolouration of the tooth. Fluorosis occurs due to changes happening during tooth formation. The

\section{ARTICLE INFORMATION}

*Corresponding Author: dhanraj@saveetha.com

Received 28th June 2020 Accepted after revision 5th August 2020

Print ISSN: 0974-6455 Online ISSN: 2321-4007 CODEN: BBRCBA

Thomson Reuters ISI Web of Science Clarivate Analytics USA and Crossref Indexed Journal

\section{Clarivate}

crossef

NAAS Journal Score 2020 (4.31) SJIF: 2020 (7.728)

A Society of Science and Nature Publication,

Bhopal India 2020. All rights reserved.

Online Contents Available at: http//www.bbrc.in/

Doi: $h$ ttp://dx.doi.org/10.21786/bbrc/13.7/10 changes are related to cell/matrix/mineral interactions as the teeth are forming. Fluoride also appears to enhance mineral precipitation in forming teeth, resulting in hypermineralized bands of enamel, which are then followed by hypomineralized bands (DenBesten and Li, 2011). Enamel fluorosis causes damage to the enamel surface (El Mourad, 2018).

Excess fluoride causes metabolic alteration in ameloblasts eventually leading to defective matrix and improper calcification of teeth and causing fluorosis of teeth (El Mourad, 2018). In moderate dental fluorosis, yellow to light brown staining is observed. Severely fluorosed teeth are more susceptible to decay, due to the loss of the outer protective layer (T. and B., 1955; DenBesten and Li, 2011).

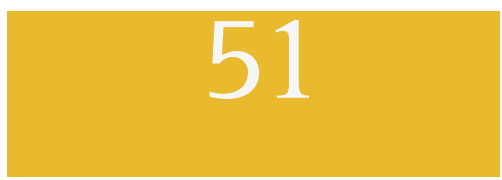


Some of the sources of fluoride are foods, water, topical applications and fluoride toothpastes (Rigo, Lodi and Garbin, 2015). The etiological agents of dental fluorosis are exposure to high levels of fluoride in drinking water, mouth rinses and dentifrices, ingestion of foods with high fluoride contents like bananas, fish, tea, potatoes (Clovis and Hargreaves, 1988).

Fluorosis is a major health problem in India and common in children (Susheela, 2018). It was identified in 1937 in Nellore, Andhra Pradesh (Shortt, Pandit and Raghavachari, 1937). Uttar Pradesh is considered as the endemic area of fluorosis in India (Pahuja, Pradhan and Nagar, 2019). In Tamil Nadu, Madurai is a known endemic fluorosis area (Meenakshi, Meenakshi and Maheshwari, 2006). Esthetics changes in permanent dentition are the greatest concern in dental fluorosis. Early manifestation of dental fluorosis is increased enamel porosity (Fejerskov, Johnson and Silverstone, 1974). Enamel hypomineralization in fluorosed teeth may be due to aberrant effects of fluoride (Aoba and Fejerskov, 2002). Diagnosis of dental fluorosis can be affected by various factors like index validity, improper drying of teeth, duration of drying, cleaning of teeth (Martins et al., 2009; Rigo, Lodi and Garbin, 2015). Differential diagnosis between fluorosis and non-fluoride-induced opacities needs to establish differences between symmetrical and asymmetrical or discrete patterns of opaque defects (Alvarez et al., 2009).

Previously our department has published extensive research on various aspects of prosthetic dentistry ('Evaluation of Corrosive Behavior of Four Nickelchromium Alloys in Artificial Saliva by Cyclic Polarization Test:An in vitro Study', 2017; Ganapathy, Kannan and Venugopalan, 2017; Jain, 2017a, 2017b; Ranganathan, Ganapathy and Jain, 2017; Ariga et al., 2018; Gupta, Ariga and Deogade, 2018; Anbu et al., 2019; Ashok and Ganapathy, 2019; Duraisamy et al., 2019; Varghese, Ramesh and Veeraiyan, 2019), this vast research experience has inspired us to research about the awareness of diagnosis of fluorosis stains. Awareness should be created among people to prevent dental diseases like caries, fluorosis and other diseases for better diagnosis and to formulate a better treatment plan (AlDaiji et al., 2018). Hence in the present study we analysed the level of awareness on diagnosis of fluorosis stains among dental students.

\section{MATERIAL AND METHODS}

The present study is a survey. A set of 12 questionnaires were prepared and distributed among students of Saveetha Dental College. The questionnaires are about fluorosis, its diagnosis and treatment. The responses are recorded and made into a pie chart.

\section{List of questions and options:}

1) Are you aware of the term fluorosis? Yes/No

2) What do you think that causes fluorosis?

Food/Drinks/Bacteria/None
3) Is fluorosis stains good for our teeth?

Yes/No

4) How do you find that the tooth contains fluorosis stains?

By checking whether the white streaks are present/

By checking the colour of the teeth/ Both/ None

5) Do you use fluoride rich toothpaste?

Yes/No

6) Are you aware of how fluorosis stains are treated?

Yes/No

7) Do you think fluorosis goes away by brushing teeth?

Yes/No

8) Do you think fluorosis weakens the tooth? Yes/No

9) Can you get rid of white spots on teeth? Yes/No

10) Do you think vitamin contents affect fluorosis? Yes/No

11) Are you aware of any specific diagnostic test for fluorosis?

Yes/No

12) Are you aware of the $S A / G A G$ test for fluoride toxicity?

Yes/No

\section{RESULTS AND DISCUSSION}

In the present study, 64\% participants were males and $36 \%$ were females. We observed that $94 \%$ were aware of fluorosis whereas 6\% were not aware [Figure 1]. 54\% participants agreed that fluorosis is caused by drinks and $23 \%$ agreed that it is caused by food intake [Figure 2]. $56 \%$ agreed that fluorosis stains are bad for our teeth [Figure 3]. Majority of the participants were aware of how to differentiate fluorosis on teeth [Figure 4] and $79 \%$ participants were aware of treatment of fluorosis stains [Figure 6]. $74 \%$ participants use fluoride rich toothpaste [Figure 5]. 57\% participants believe that fluorosis goes away by brushing the teeth [Figure 7]. $75 \%$ participants were aware that fluorosis weakens the tooth [Figure 8]. 71\% participants were aware that white spots can be treated [Figure 9]. 77\% participants were aware that vitamin content affects fluorosis [Figure 10]. $62 \%$ participants were aware of the diagnostic measures [Figure 11] and 55\% participants were aware of the SA/GAG test, which is used to check fluoride toxicity [Figure 12].

From the results obtained we observed that only less people were not aware of fluorosis stains and majority of them were aware of the cause of fluorosis. Most of them said that the cause is consumption of drinks. Majority of the students are aware of the diagnosis and treatment plan for fluorosis stains.

There are similar studies conducted to know the level of awareness on fluorosis stains and diagnostic measures. 
A study was conducted by Fasil Kenea Duguma et al where they reported the awareness level on fluorosis was as high (concordant to the present study) but the awareness on treatments and their success rate were relatively low (Duguma and Jeylan, 2019). Most of the respondents in the present study mentioned the cause of fluorosis as drinking water and this is in concordant to the study conducted by Fasil Kenea Duguma et al (Duguma and Jeylan, 2019). Fasil Kenea Duguma et al also have reported that dental fluorosis causes impact on general health (Duguma and Jeylan, 2019). Reem Aldaigy et al conducted a similar study where they reported the diagnosis based on dean's fluorosis index (AlDaiji et al., 2018).

Figure 1: Pie chart representing the awareness level on fluorosis. Blue denotes participants who are aware and red denotes participants who are not aware. $94 \%$ participants were aware of the term fluorosis whereas $6 \%$ were not aware

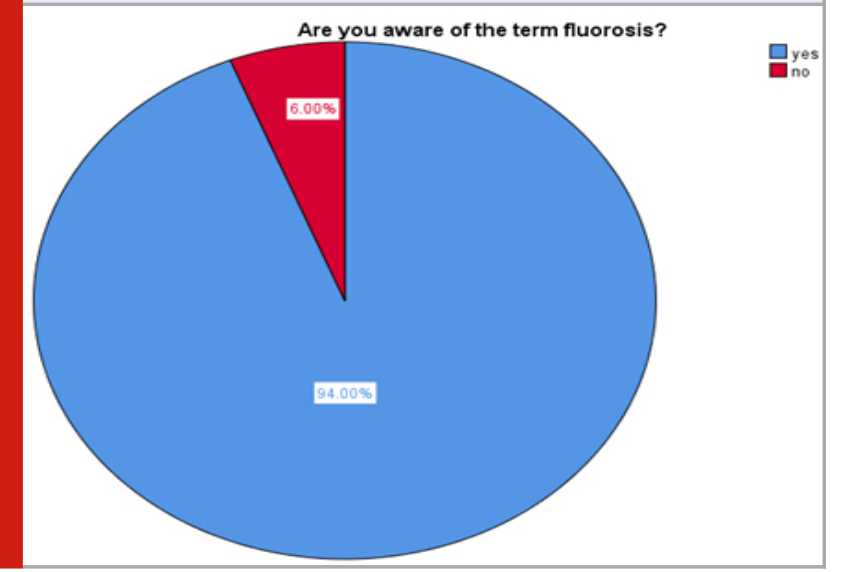

Figure 2: Pie chart representing the cause of fluorosis. Blue denotes participants saying food, red denotes participants saying drinks, green denotes participants saying bacteria and orange denotes participants saying none. 54\% participants said that the cause is drinks, followed by food $(23 \%)$, bacteria $(16 \%)$ and none being the least $(7 \%)$.

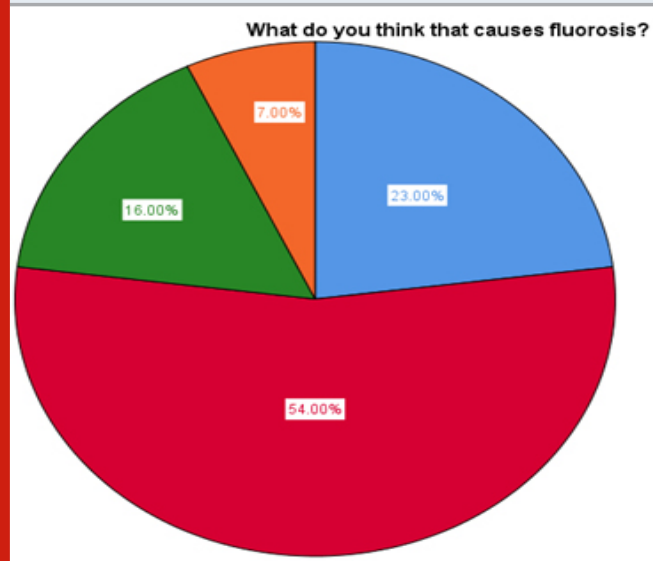

Figure 3: Pie chart representing the status of fluorosis on our teeth. Blue denotes participants who are saying yes and red denotes participants who are saying no. $44 \%$ participants said yes and $56 \%$ said no

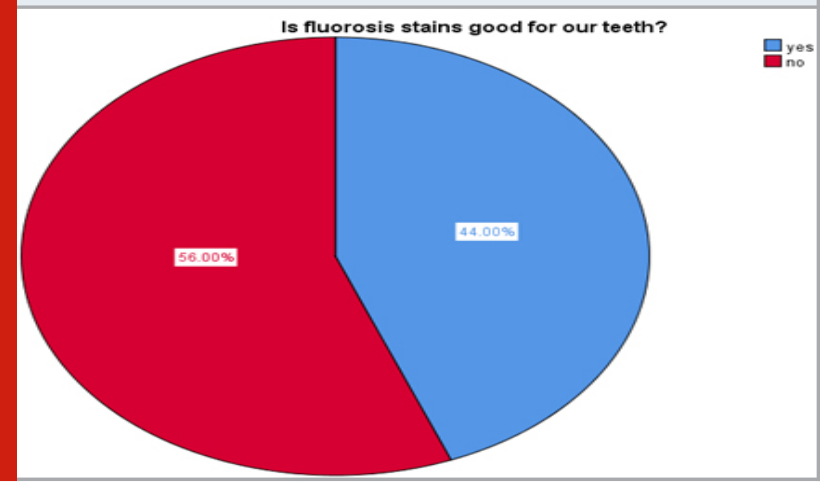

Figure 4: Pie chart representing the way to identify the fluorosis stains in our teeth. Blue denotes participants who are saying that they can identify by checking whether the white streaks are present, red denotes participants who are saying that they can identify by checking the colour of the teeth, green denotes participants who are saying both the options and orange denotes participants who are saying none of the options. 52\% participants said both the options followed by participants who are saying that they can identify by checking the colour of the teeth $(27 \%)$, participants who are saying that they can identify by checking whether the white streaks are present (19\%) and participants who are saying none (2\%).

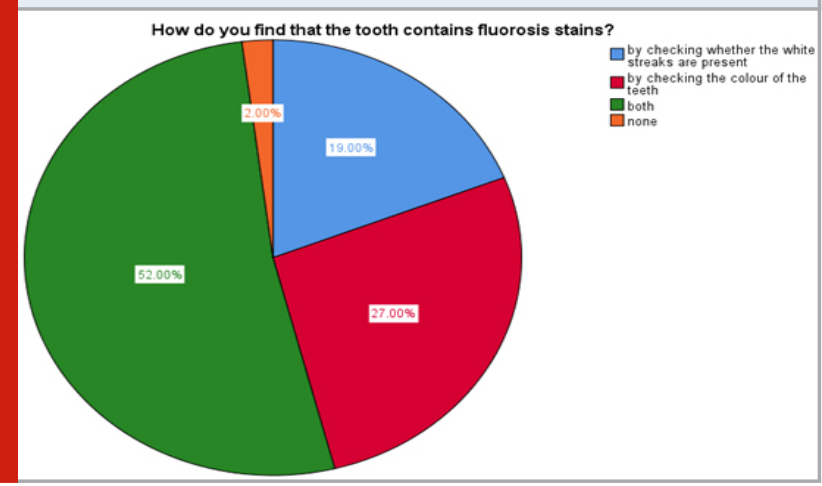

Figure 5: Pie chart representing the number of participants using fluoride rich toothpaste. Blue denotes participants who are saying yes and red denotes participants who are saying no. 74\% participants said yes and $26 \%$ participants said no

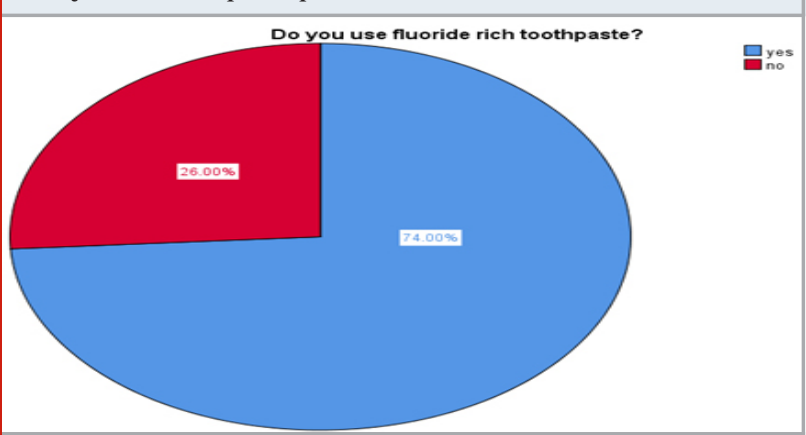


Figure 6: Pie chart representing how many of the participants are aware of treating the fluorosis stains and how many of them are not aware. Blue denotes participants who are saying yes and red denotes participants who are saying no. $79 \%$ participants said yes and 21\% participants said no

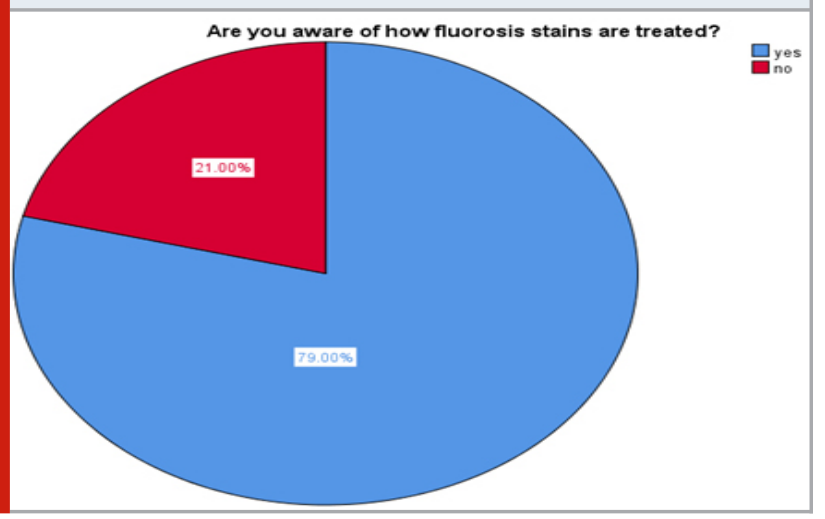

Figure 7: Pie chart representing the number of participants who believe in treating fluorosis stains by brushing the teeth. Blue denotes participants who are saying yes and red denotes participants who are saying no. 57\% participants said yes and 43\% participants said no

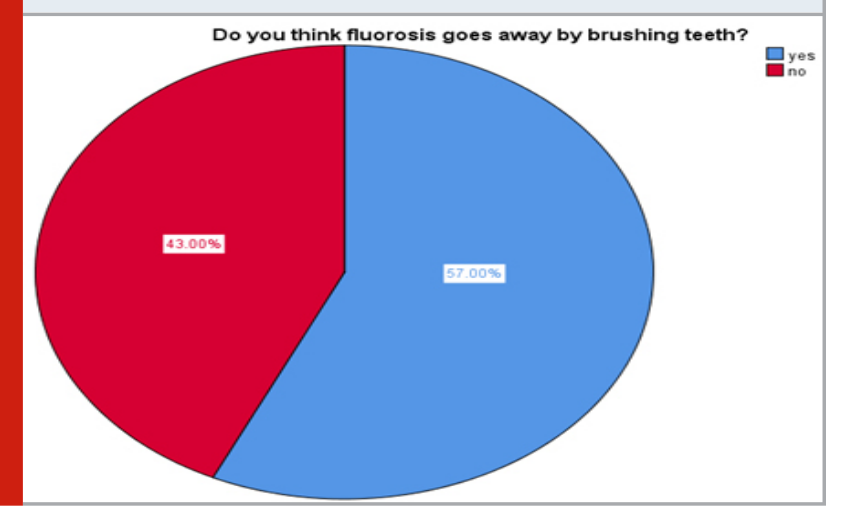

Figure 8: Pie chart representing how many participants are aware that fluorosis stain weakens the tooth and how many of them are not aware. Blue denotes participants who are saying yes and red denotes participants who are saying no. $75 \%$ participants said yes and 25\% participants said no

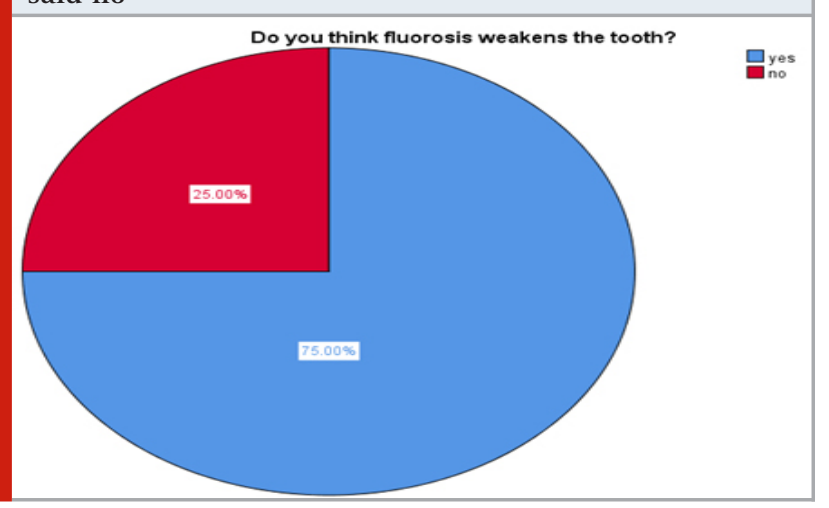

Figure 9: Pie chart representing the number of participants who believe that they can get rid of white spots on teeth. Blue denotes participants who are saying yes and red denotes participants who are saying no. 71\% participants said yes and 29\% participants said no

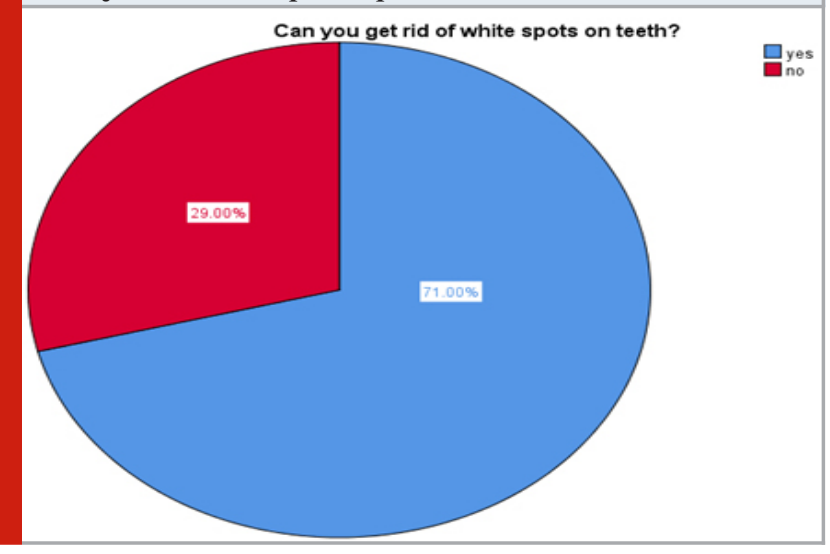

Figure 10: Pie chart representing the number of participants who believe that vitamin content can affect fluorosis. Blue denotes participants who are saying yes and red denotes participants who are saying no. 77\% participants said yes and 23\% participants said no

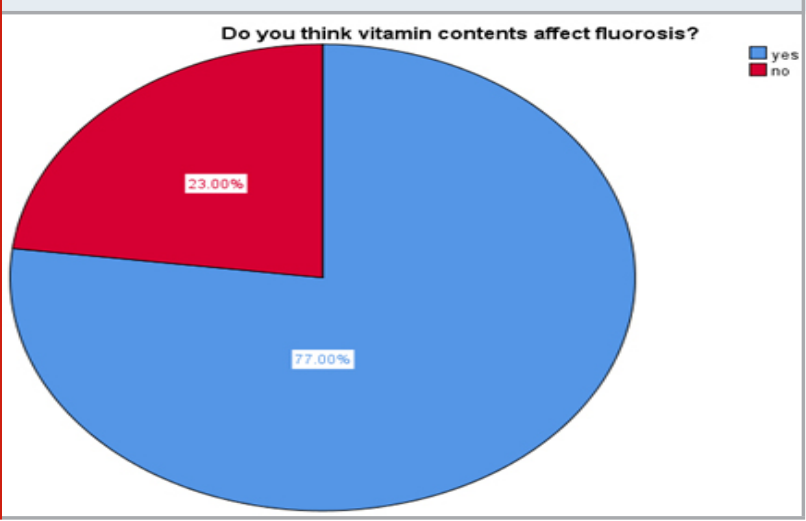

Figure 11: Pie chart representing the participant's awareness level on specific diagnostic tests. Blue denotes participants who are saying yes and red denotes participants who are saying no. 62\% participants said yes and 38\% participants said no

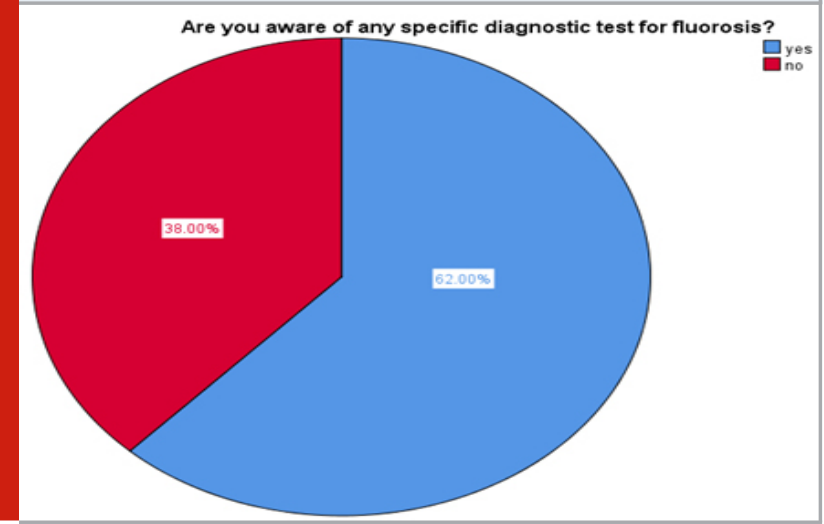


Figure 12: Pie chart representing the participant's awareness level on SA/GAG test for fluoride toxicity. Blue denotes participants who are saying yes and red denotes participants who are saying no. 55\% participants said yes and 45\% participants said no.
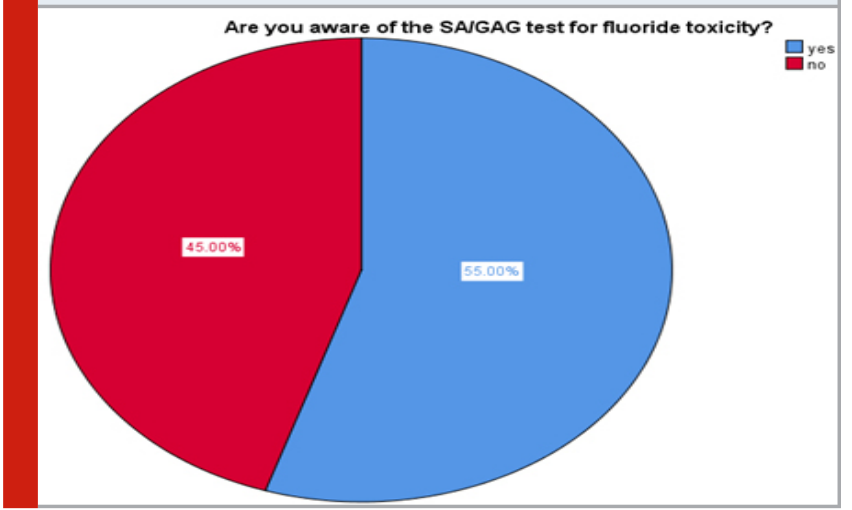

Majority of the respondents in the present study use fluoride rich toothpaste and some studies have reported the prevalence of fluorosis due to usage of fluoride rich toothpaste. Hence the fluoride composition in the toothpaste should be present at a limited range to prevent fluorosis (Tiwari, Kaur and Sodhi, 2010). SA/GAG test is a diagnostic test used to measure fluoride toxicity (Jha et al., 1982) and the present study showed that the majority of the respondents were aware of the diagnostic test. The SA/GAG test can also be used as a diagnostic test for ankylosing spondylitis (Susheela et al., 1988).

Pahuja $\mathrm{M}$ et al conducted a study where they assessed the awareness level among the rural population and they reported that the majority of the participants were aware of dental fluorosis and treatments done but they were not aware of its consequences and did not consult a dentist which is contrary to the present study as majority of the respondents were aware that fluorosis stains weaken the tooth (Pahuja, Pradhan and Nagar, 2019). Another study was conducted by Yadav R et al where they conducted a survey among children and reported that most of the children were not aware of fluorosis and most of the children worried about esthetic concerns (Yadav, Yadav and Oberoi, 2014). Hence a proper awareness should be created among the people about its consequences and treatment plans (Pahuja, Pradhan and Nagar, 2019), (Yadav, Yadav and Oberoi, 2014).

One of the main etiologies for fluorosis is consuming fluoride rich foods and water resulting in fluorosis and the study conducted by Anand Verma et al have reported this (Verma et al., 2017). Even in the present study most of the respondents were aware of the cause. Treatment plan should be formulated based on severity of fluorosis and this can be achieved by Dean's fluorosis index, which is widely used to measure the severity of fluorosis (Akpata, 2001). The present study is a single centered study with a small sample size. The future scope includes multi centered study with a large population and including other diagnostic measures for creating awareness in all kinds of population.

\section{CONCLUSION}

Thus the present study showed that there is proper awareness on fluorosis stains and its diagnosis among dental students. Though there is proper awareness of fluorosis stains, there are few populations who are not aware of the diagnostic measures. Hence proper awareness on fluorosis should be created among students for proper diagnosis and treatment planning.

\section{ACKNOWLEDGEMENTS}

The author would like to acknowledge the help and support by the Department of Information Technology of Saveetha Dental College and Hospital and the management for their constant assistance with the research.

Conflict of Interest: The authors declare that there were no conflicts of interest in the present study.

\section{REFERENCES}

Akpata, E. S. (2001) 'Occurrence and management of dental fluorosis', International Dental Journal, pp. 325-333. doi: 10.1002/j.1875-595x.2001.tb00845.x.

AlDaiji, R. et al. (2018) 'Awareness of dental fluorosis among undergraduate dental students in Riyadh region: a survey based study', International Journal of Research in Medical Sciences, p. 3852. doi: 10.18203/2320-6012. ijrms20184739.

Alvarez, J. A. et al. (2009) 'Dental fluorosis: exposure, prevention and management', J Clin Exp Dent, 1(1), pp. 14-18.

Anbu, R. T. et al. (2019) 'Comparison of the Efficacy of Three Different Bone Regeneration Materials: An Animal Study', European journal of dentistry, 13(1), pp. 22-28.

Aoba, T. and Fejerskov, 0. (2002) 'Dental fluorosis: chemistry and biology', Critical reviews in oral biology and medicine: an official publication of the American Association of Oral Biologists, 13(2), pp. 155-170.

Ariga, P. et al. (2018) 'Determination of Correlation of Width of Maxillary Anterior Teeth using Extraoral and Intraoral Factors in Indian Population: A Systematic Review', World Journal of Dentistry, 9(1), pp. 68-75.

Ashok, V. and Ganapathy, D. (2019) 'A geometrical method to classify face forms', Journal of oral biology and craniofacial research, 9(3), pp. 232-235.

Clovis, J. and Hargreaves, J. A. (1988) 'Fluoride intake from beverage consumption', Community Dentistry and Oral Epidemiology, pp. 11-15. doi: 10.1111/j.16000528.1988.tb00545.x.

DenBesten, P. and Li, W. (2011) 'Chronic Fluoride Toxicity: Dental Fluorosis', Fluoride and the Oral 
Environment, pp. 81-96. doi: 10.1159/000327028. Duguma, F. K. and Jeylan, M. (2019) 'Assessment on Knowledge, Attitude and Practice Towards Dental Fluorosis and its Impact Among Goro Secondary School Students in Adama Town, Ethiopia, June 2016', Advances in Dentistry \& Oral Health. Juniper Publishers Inc., 11(2), pp. 66-79.

Duraisamy, R. et al. (2019) 'Compatibility of Nonoriginal Abutments With Implants: Evaluation of Microgap at the Implant-Abutment Interface, With Original and Nonoriginal Abutments', Implant dentistry, 28(3), pp. 289-295.

El Mourad, A. M. (2018) 'Aesthetic Rehabilitation of a Severe Dental Fluorosis Case with Ceramic Veneers: A Step-by-Step Guide', Case reports in dentistry, 2018, p. 4063165.

Evaluation of Corrosive Behavior of Four Nickelchromium Alloys in Artificial Saliva by Cyclic Polarization Test:An in vitro Study' (2017) World Journal of Dentistry, 8(6), pp. 477-482.

Fejerskov, 0., Johnson, N. W. and Silverstone, L. M. (1974) 'The ultrastructure of fluorosed human dental enamel', Scandinavian journal of dental research, 82(5), pp. 357-372.

Ganapathy, D. M., Kannan, A. and Venugopalan, S. (2017) 'Effect of Coated Surfaces influencing Screw Loosening in Implants: A Systematic Review and Meta-analysis', World Journal of Dentistry, 8(6), pp. 496-502.

Gupta, P., Ariga, P. and Deogade, S. C. (2018) 'Effect of Monopoly-coating Agent on the Surface Roughness of a Tissue Conditioner Subjected to Cleansing and Disinfection: A Contact Profilometric Study', Contemporary clinical dentistry, 9(Suppl 1), pp. S122S126.

Jain, A. R. (2017a) 'Clinical and Functional Outcomes of Implant Prostheses in Fibula Free Flaps', World Journal of Dentistry, 8(3), pp. 171-176.

Jain, A. R. (2017b) 'Prevalence of Partial Edentulousness and Treatment needs in Rural Population of South India', World Journal of Dentistry, 8(3), pp. 213-217. Jha, M. et al. (1982) 'Excessive Ingestion of Fluoride and the Significance of Sialic Acid: Glycosaminoglycans in the Serum of Rabbit and Human Subjects', Journal of Toxicology: Clinical Toxicology, pp. 1023-1030. doi: 10.3109/15563658208992537.

Martins, C. C. et al. (2009) 'Agreement in the diagnosis of dental fluorosis in central incisors performed by a standardized photographic method and clinical examination', Cadernos de Saúde Pública, pp. 10171024. doi: 10.1590/s0102-311x2009000500008.

Meenakshi, Meenakshi and Maheshwari, R. C. (2006)
'Fluoride in drinking water and its removal', Journal of Hazardous Materials, pp. 456-463. doi: 10.1016/j. jhazmat.2006.02.024.

Pahuja, M., Pradhan, S. and Nagar, V. (2019) 'Knowledge, attitude, and esthetic perceptions about dental fluorosis amongst the rural population in Meerut District, Uttar Pradesh', Indian Journal of Dental Sciences, p. 12. doi: 10.4103/ijds.ijds_65_18.

Ranganathan, H., Ganapathy, D. M. and Jain, A. R. (2017) 'Cervical and Incisal Marginal Discrepancy in Ceramic Laminate Veneering Materials: A SEM Analysis', Contemporary clinical dentistry, 8(2), pp. 272-278.

Rigo, L., Lodi, L. and Garbin, R. R. (2015) 'Differential diagnosis of dental fluorosis made by undergraduate dental students', Einstein (São Paulo), pp. 547-554. doi: 10.1590/s1679-45082015ao3472.

Shortt, H. E., Pandit, C. G. and Raghavachari, T. N. S. (1937) 'Endemic Fluorosis in the Nellore District of South India', Indian medical gazette, 72(7), pp. 396-398.

Susheela, A. K. et al. (1988) 'Circulating levels of sialic acid and glycosaminoglycans: a diagnostic test for ankylosing spondylitis', Annals of the rheumatic diseases, 47(10), pp. 833-837.

Susheela, A. K. (2018) 'Fluorosis and Iodine Deficiency Disorders in India', Current Science, p. 860. doi: 10.18520/cs/v115/i5/860-867.

Tiwari, P., Kaur, S. and Sodhi, A. (2010) 'Dental fluorosis and its association with the use of fluoridated toothpaste among middle school students of Delhi', Indian journal of medical sciences, 64(1), pp. 1-6.

T., O. and B., W. (1955) 'Stain in mottled enamel', The Journal of the American Dental Association, pp. 536-538. doi: 10.14219/jada.archive.1955.0095.

Varghese, S. S., Ramesh, A. and Veeraiyan, D. N. (2019) 'Blended Module-Based Teaching in Biostatistics and Research Methodology: A Retrospective Study with Postgraduate Dental Students', Journal of dental education, 83(4), pp. 445-450.

Verma, A. et al. (2017) 'High prevalence of dental fluorosis among adolescents is a growing concern: a school based cross-sectional study from Southern India', Environmental health and preventive medicine, 22(1), p. 17.

Yadav, R., Yadav, A. and Oberoi, S. S. (2014) 'Knowledge, Attitude and Aesthetic Perceptions about Dental Fluorosis among 12-15 Years Old Government School Children in Farukh Nagar, Haryana', Journal of Oral Health and Community Dentistry, pp. 1-5. doi: 10.5005/ johcd-8-1-1. 